\title{
Farklı yetiştirme koşullarının zencefil (Zingiber officinale Roscoe)'in verim ve kalitesi üzerine etkileri
}

\section{The effects of different growing conditions on yield and quality parameters of ginger (Zingiber officinale)}

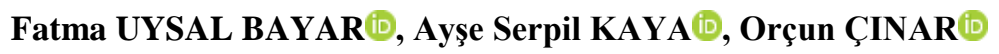 \\ Batı Akdeniz Tarımsal Araştırma Enstitüsü, Antalya \\ Sorumlu yazar (Corresponding author): F. Uysal Bayar, e-posta (e-mail): uysal.fatma@tarimorman.gov.tr \\ Yazar(lar) e-posta (Author e-mail): ayseserpil.kaya@tarimorman.gov.tr, orcun.cinar@ tarimorman.gov.tr
}

\section{MAKALE BİLGİSİ}

Alınış tarihi 15 Mayıs 2020

Düzeltilme tarihi 15 Aralı 2020

Kabul tarihi 25 Ocak 2021

\section{Anahtar Kelimeler:}

Adaptasyon

Taze yumru

Uçucu yă̆

6-shogaol

Gingerol

\section{ÖZ}

Zencefil (Zingiber officinale Roscoe), Zingiberaceae familyasına dahil olup, antik çağlardan beri bilinen bir bitkidir. Günümüzde, birçok sektörde yaygın olarak kullanılmaktadır. Bu çalışma ile dünya pazarında ekonomik değeri yüksek ve ithalata konu olan zencefilin, sera ve gölge alanda, farklı dikim zamanlarındaki verim ve kalite paramatrelerini belirlemek amaçlanmıștır. Çalışmada, bitki boyu (cm), gövde sayısı (adet), taze ve kuru yumru ağırlığı ( $\mathrm{g}$ bitki ${ }^{1}$ ), 6-shogaol, 6-gingerol, uçucu yağ oranı (\%) ve uçucu yağ bileşen (\%) parametreleri 2 y1l süreyle gözlemlenmiştir. En uzun bitki boyu $126.92 \mathrm{~cm}$ olarak belirlenirken en fazla gövde

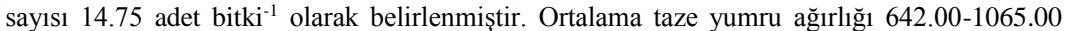
$\mathrm{g} \mathrm{bitki}^{-1}$ arasında değişim gösterirken, ortalama kuru yumru ağırlığ $642.00-1076.00 \mathrm{~g} \mathrm{bitki}^{-1}$ arasında değişim göstermiştir. 6-shogaol en yüksek $4.06 \mathrm{mg} \mathrm{g}^{-1}$ olarak tespit edilirken, en yüksek gingerol miktarı $7.19 \mathrm{mg} \mathrm{g}^{-1}$ olarak tespit edilmiştir. Ortalama uçucu yağ oranları \% 0.89-1.40 arasında değişim göstermiştir. Ayrıca uçucu yağda ortalama zingiberene, beta sesquiphellandrene ve beta bisabolene sirasiyla \%37.40-42.73, \%20.05-23.38 ve \%6.23-13.53 oranları tespit edilmiştir. Bu çalışma ile zencefile ait ülkemizde adaptasyon çalışmaları başlamış olup, Antalya'da sera koşullarında, şubat dikimi en uygun dikim zamanı olarak belirlenmiştir.

\section{ARTICLE INFO}

Received 15 May 2020

Received in revised form 15 December 2020 Accepted 25 January 2021

\section{Keywords:}

Adaptation

Fresh tuber

Essential oil

6-shogaol

Gingerol

\begin{abstract}
Ginger (Zingiber officinale) which is a member of Zingiberaceae family, is a plant which is known since ancient times. Nowadays, it is used as widely in many sectors. In this study, it was aimed that to determine the yield and quality parameters of ginger which has higher economical value at world markets and is imported. It was grown at greenhouse and shade conditions and it was planted at different times. In the study, plant height $(\mathrm{cm})$, number of stems (pcs), fresh and dry tuber weight $\left(\mathrm{g} \mathrm{plant}^{-1}\right)$, essential oil rate (\%), essential oil components (\%), 6-shogaol and 6-gingerol contents were evaluated during 2 years. The longest plant height was determined as $126.92 \mathrm{~cm}$ while the maximal stem number was determined as $14.75 \mathrm{pcs}$ plant $^{-1}$. The average fresh tuber weight varied between 642.00 and $1065.00 \mathrm{~g} \mathrm{plant}^{-1}$ while the average dried tuber weight varied between 642.00 and 1076.00 $\mathrm{g}$ plant ${ }^{-1}$. The highest 6 -shogaol content was detected as $4.06 \mathrm{mg} \mathrm{g}^{-1}$ and the highest gingerol content was detected as $7.19 \mathrm{mg} \mathrm{g}^{-1}$. The average essential oil rates varied between $0.89 \%$ and $1.40 \%$. Besides, in the essential oil, the average zingiberene, beta-sesquiphellandrene and beta-bisabolene contents were detected as $37.40-42.73 \%, 20.05-23.38 \%$ and $6.23-13.53 \%$. In this study, the adaptation studies of ginger were started in our country, the most favorable planting time was determined as February planting.
\end{abstract}




\section{Giriş}

Zencefil (Zingiber officinale), Hindistan ve Çin'de antik çağlardan beri bilinen hem baharat hem de tıbbi bir bitki olarak kullanılan, dünya çapında en popüler baharatlardan biridir. Dünyada yaygın olarak gıda, ilaç, içecek vb. kullanım alanı olan zencefil (Hayden ve ark. 2004; Tropical Biodiversity 2020) Hindistan, Çin, Güney Doğu Asya, Batı Hint Adaları ve Meksika'da doğal olarak yetişmektedir (Ghosh ve Mandi 2011; Nair 2013). Dünya pazarında ekonomik değeri yüksek olan zencefilin, ülkemizde yok denecek kadar az üretimi bulunmaktadır. Arslan ve ark. (2015), Türkiye'de zencefilin ithal edilen ilk 20 tıbbi aromatik bitki arasında, miktar bakımından yaklaşık 1162 ton ile altıncı sırada, değer bakımından 1017000 dolar ile 10. sirada yer aldığını bildirmişlerdir. Temel ve ark. (2018) ise, 2015 yılında zencefilin de içinde bulunduğu bir grup baharatın ithal edildiğini ve bunlara 46.5 milyon dolar ödendiğini ifade etmişlerdir. Önemli ekonomik değere sahip olan zencefil, uçucu yağ ve fenolik bileşikler gibi biyokimyasal özelliklere sahiptir. Zencefilde \%1-3 oranında uçucu yağ bulunmaktadır. Bu uçucu yağda bazı aktif bileşenler yer alır. Uçucu yağda yüksek oranda seskiterpenler, monoterpenler ve alifatik bileşikler vardır. Baskın seskiterpenler, bisabolen ve zingiberene'dir. Zencefilde bulunan fenolik bileşikler ise shogaol ve gingerol bileşenleridir. Aktif bileşenlerin ve fenolik bileşenlerin oranları, yetiştirme koşullarına göre değişim göstermektedir (Kemper 1999). Tropik ve yarı tropik iklimlerde yetiştiriciliği yapılan zencefile ait ülkemizde daha önce yapılmış herhangi bir adaptasyon çalışması bulunmamaktadır. Yarı tropik iklim kuşağını da içine alan Türkiye, konumu gereği birçok doğal bitki çeşitliliğine sahiptir. Ayrıca farklı iklim kuşaklarına sahip olan ülkemizde, dünyanın farklı yerlerinde yayılış gösteren birçok türün adaptasyon çalışmaları ile adapte edilmiş ve yetiştiriciliği yapılmaktadır. Ülkemizde tüketimi gün geçtikçe artan ve ithalata konu olan zencefilde, adaptasyon çalışmalarının faydalı olacağı düşünülmüsstür. Bu çalışma ile zencefilin sera ve gölge alanda, farklı dikim zamanlarındaki verim ve kalite performansları belirlenmiştir. Ayrıca bu çalışma, ülkemizde yapılan ilk adaptasyon çalışması olma özelliğine sahiptir.

\section{Materyal ve Metot}

Çalı̧̧ma; Batı Akdeniz Tarımsal Araştırma Enstitüsünde 2017-2018 yılları arasında, 1sıtması plastik sera ve \%75'lik gölge tülü ile oluşturulmuş gölge alanda, 2 yıl süreyle yürütülmüştür. Materyal olarak, Çin menşeili zencefil yumruları kullanılmıştır. Materyal, ithalatçı firmalardan soğuk zincir kırılmadan, temin edilmiştir. Sera ve gölge alanda yetiştiricilik, (1:1) torf+perlit karışımı kullanılarak, 25 litrelik saksılarda yapılmıştır. Deneme, her iki alanda da 3 farklı dikim zamanında (15 Ocak, 15 Şubat, 15 Mart), 10 saksı, her saksıda 1 tohumluk yumru olacak şekilde 3 tekerrürlü olarak kurulmuştur. Dikimler, 25 litrelik saksıların 10 litrelik kısmı torf + perlit karıșımı ile doldurularak 3-4 göz içeren 50-60 gr ağırlığındaki yumruların 5 cm derinliğe dikilmesiyle gerçekleşmiştir (White ve ark. 2013). Saksının diğer kısımları 3 farklı zamanda hazırlanmış torf-perlit karışımıyla doldurulmuştur. İlk ilave, dikimden 4 ay sonra bitkiler belirli bir büyüklüğe gelince $(60 \mathrm{~cm})$, ikinci ortam ilave dikimden 5 ay sonra, üçüncü ilave ise 7 ay sonra gerçekleşmiştir (Hepperly ve ark. 2004). Hoagland ve Arnon (1950) tarafindan bildirilen besin çözeltisi gübreleme amaçlı olarak kullanılmıştır. Gübrelemede kullanılan standart besin solüsyonu Çizelge 1'de verilmiştir. Dikimden önce saksı ortamının tarla kapasitesi ve solma noktası belirlenmiş ve tarla kapasitesinin \%30'u tüketildiği zaman, sulama $2 \mathrm{~L} \mathrm{saat}^{-1}$ debili damlatıcılar ile her saksıya bir damlatıcı gelecek şekilde gerçekleşmiştir. Yapraklar sarıya dönüp, \%50 kuruma başladığı zaman dikimden sonra 10. ayda hasat işlemi gerçekleşmiştir. Hasat yapmadan bir ay önce toprak seviyesinden en uç noktaya kadar ölçülerek bitki boyu (cm) ve yumrudan çıkan gözlerin oluşturduğu yalancı gövde sayısı sayılarak gövde sayısı (adet) belirlenmiştir. Hasat ile birlikte, taze ve kuru yumru ağırlığ 1 (g bitki $\left.{ }^{-1}\right)$, akan su altında temizlenerek tartılmış ve kuru yumru ağırlığı $\left(\mathrm{g} \mathrm{bitki}^{-1}\right), 40^{0} \mathrm{C}$ derecede sabit ağırlığa gelinceye kadar kurutma firınında kurutularak belirlenmiştir.

Fenolik Bileşen (6- shogaol ve 6-gingerol) analizleri öncesinde ekstraksiyon işlemi Cemeroğlu (2010)'un geliştirdiği metoda göre yapılmıştır. 6-gingerol ve 6-shogaol maddelerinin miktar tespiti ise s1v1 kromatografisi-kütle spektrometresi (LC-MS/MS, Agilent 6430) cihazı kullanılarak belirlenmiştir (Fischer ve ark. 2011). Uçucu yağ oranı Klevenger distilasyon cihazı kullanılarak hidrodistilasyon yöntemi ile belirlenmiş̧ir. Kurutulmuş $20 \mathrm{~g}$ numune cam clevenger balonuna yerleştirilmiş ve üzerine $200 \mathrm{~mL}$ saf su ilave edilmiştir. Yaklaşık 2 saat süre ile hidrodistilasyon işlemine tabi tutulmuştur. Daha sonra dereceli kısımda biriken ve su ile faz farkı oluşturan uçucu yağ numunesinin okuması yapılarak sonuç $\mathrm{mL}$ cinsinden kaydedilmiştir. Uçucu yağ oranı, tartım miktarından yola çıkarak yüzde olarak hesaplanmıştır (TSE 2011). Uçucu yăg bileşenleri analizi GC-MS (Gaz kromatografisi (Agilent 7890A)-kütle detektör (Agilent 5975C) cihazı kullanılarak tespit edilmiştir (Uysal Bayar ve Çınar 2020). Çalışmada elde edilen veriler Genel Linear Model Esas1 ile \%5 ve \%1 önemlilik düzeylerine göre varyans analizlerine tabi tutulmuştur. Önemli farklılıkların ortaya çıktığı durumlarda, ortalamaları karşılaştırmak için \%5 önemlilik düzeyinde Duncan testi uygulanmıştır (Gülümser ve ark. 2006).

Çizelge 1. Gübrelemede kullanılan standart besin solüsyonu Hoagland ve Arnon (1950).

Table 1. Standard nutrition solution used in fertilization Hoagland and Arnon (1950).

\begin{tabular}{|c|c|c|}
\hline \multicolumn{3}{|c|}{ Standart Besin Solüsyonu (Yüzde Birlik Stok) } \\
\hline STOK-A $\left(\mathrm{g} \mathrm{L}^{-1}\right)$ & STOK- B $\left(\mathrm{g} \mathrm{L}^{-1}\right)$ & ASÍT STOK $\left(\mathrm{mL} \mathrm{L} \mathrm{L}^{-1}\right)$ \\
\hline $44.86 \mathrm{~g} \mathrm{~L} \mathrm{~L}^{-1}$ Kalsiyum Nitrat & $11.5 \mathrm{~g} \mathrm{~L}^{-1}$ Mono Amonyum Fosfat (MAP) & $26.7 \mathrm{ml} \mathrm{Nitrik}$ Asit L $\mathrm{L}^{-1}$ (\%67HNO3) \\
\hline $24.77 \mathrm{~g} \mathrm{~L}^{-1}$ Potasyum Nitrat & $24.77 \mathrm{~g} \mathrm{~L}^{-1}$ Potasyum Nitrat & \\
\hline $5.68 \mathrm{~g} \mathrm{Fe}-\mathrm{EDDHA}$ (Sequestren) & $8.71 \mathrm{~g} \mathrm{~L}^{-1}$ Potasyum Sülfat & \\
\hline & $24.64 \mathrm{~g} \mathrm{~L}^{-1}$ Magnezyum Sülfat & \\
\hline & $0.45 \mathrm{~g}$ Boraks $(\% 11 \mathrm{~B})$ & \\
\hline & $0.17 \mathrm{~g}$ Mangan Sülfat & \\
\hline & $0.23 \mathrm{~g}$ Çinko Sülfat & \\
\hline & $0.010 \mathrm{~g}$ Bakır Sülfat & \\
\hline & $0.012 \mathrm{~g} \mathrm{Na}-$ Molibdat & \\
\hline
\end{tabular}




\section{Bulgular ve Tartışma}

\subsection{Bitki boyu ve gövde saylsı}

Araştırmada incelenen bitki boyu değerleri Çizelge 2'de verilmiştir. Elde edilen veriler arasında istatistiksel bir fark bulunmamıştır. Bitki boyu 102.25-126.92 cm arasında değişim göstermiştir. En uzun bitki boyu $(126.92 \mathrm{~cm})$; ilk yıl, gölge alanda mart dikiminden elde edilmiştir. Bunu, aynı yıl gölge alanda gerçekleştirilen şubat dikiminden elde edilen değer $(125.67 \mathrm{~cm})$ takip etmiştir. Pandey ve ark. (2017), orman altında yaptıkları çalışmada, bitki boyunu $27.78-40.67 \mathrm{~cm}$ arasında tespit ederken, Woelore ve ark. (2016), yaptıkları bir çalışmada bitki boyunu $38.76-44.10 \mathrm{~cm}$ arasında belirlemişlerdir. Pandey ve ark. (2017) ve Woelore ve ark. (2016)'nın elde ettiği bitki boyu değerleri, yürütülen çalışmadan elde edilen değerlerinden (102.25-126.92 cm) oldukça düşüktür.

Araştırmada incelenen gövde sayıları arasında istatistiksel bir fark bulunmamıştır. İlk yıl gövde sayısı 9.03-12.50 adet bitki ${ }^{-1}$ arasında değişim gösterirken, ikinci y1l 12.17-14.75 adet bitki ${ }^{-1}$ arasında değişim göstermiştir. Dikim zamanı açısından değerlendirilecek olursa en fazla gövde sayısı (14.69 adet bitki ${ }^{-1}$ ) ikinci yıl şubat dikiminden elde edilmiştir (Çizelge 3). Nijerya'da yürütülen bir gübreleme çalışmasında, en fazla gövde sayısı (2.8 adet) kanatlı gübre uygulamasından elde edilmiştir (Egbuchua ve Enujeke 2013). Babu ve ark. (2017), ise yürüttükleri bir çeşit denemesinde, en fazla gövde sayısını 28.56 adet bitki ${ }^{-1}$ olarak belirlemişlerdir. Tarafımızdan yürütülen çalışmada elde edilen gövde sayısı değerleri; Egbuchua ve Enujeke (2013) tarafindan yürütülen çalışmalardan elde edilen gövde sayısı değerlerinden oldukça yüksek bulunurken, Babu ve ark. (2017), tarafından yürütülen çalışmalardan elde edilen değerlerden daha düşük bulunmuştur. Farklı araştırmalarda elde edilen farklı bitki boyları ve dal sayıları, denemenin yürütüldüğü alandaki toprak ve iklim farklılığı ile açıklanabileceği gibi, çalışma konularının ve kullanılan bitkisel materyalin farklılığ 1 ile de açıklanabilir.

\subsection{Taze ve kuru yumru verimi}

Çalışmada elde edilen taze yumru verim değerleri Çizelge 4'de verilmiştir. Çizelgede görüldüğü gibi ilk yıl dikim zamanı, yetiştirme ortamı ve dikim zamanı $\mathrm{x}$ yetiştirme ortamı interaksiyonu önemsiz bulunurken, ikinci yıl dikim zaman1, yetiştirme ortamı ve dikim zamanı $x$ yetiştirme ortamı interaksiyonu $\% 1$ düzeyinde önemli bulunmuştur. Dikim zamanı $\mathrm{x}$ yetiştirme ortamı interaksiyonu incelendiğinde, taze yumru verimi bakımından en yüksek değer ikinci yıl serada, şubat dikiminden (1076.75 $\mathrm{g} \mathrm{bitki}^{-1}$ ) elde edilirken, bunu aynı grupta yer alan serada mart dikimi (1024.94 $\mathrm{g} \mathrm{bitki}^{-1}$ ) takip etmiştir. Dikim zamanı açısından bitki başına taze yumru ağırlığı değerleri incelendiğinde en fazla yumru ağırlığı $(949.25$ $\mathrm{g} \mathrm{bitki}^{-1}$ ) ilk yıl şubat ayında elde edilirken, yetiştirme ortamı açısından en fazla yumru ağırlığı (946.72 $\left.\mathrm{g} \mathrm{bitki}^{-1}\right)$ ilk yıl sera ortamından elde edilmiştir.

Kuru yumru verimi bakımından, ilk yıl dikim zamanı $\mathrm{x}$ yetiştirme ortamı interaksiyonu önemsiz bulunurken, ikinci y1l $\% 1$ düzeyinde önemli bulunmuştur. Dikim zamanı ve yetiştirme ortamı açısından değerler arasındaki fark ilk yıl \%5, ikinci yıl $\% 1$ düzeyinde önemli bulunmuştur. Kuru yumru verim değerleri ilk yıl 79.28-137.43 $\mathrm{g} \mathrm{bitki}^{-1}$ arasında tespit edilirken ikinci yıl 58.37-132.00 $\mathrm{g} \mathrm{bitki}^{-1}$ arasında tespit edilmiştir. Dikim zamanı açısından bitki başına kuru yumru ağırlığı değerleri incelendiğinde en fazla kuru yumru ağırlığ $\left(118.16 \mathrm{~g} \mathrm{bitki}^{-1}\right)$ ilk y1l şubat ayında elde edilirken, yetiştirme ortamı açısından en fazla kuru yumru ağırlığı (117.32 $\left.\mathrm{g} \mathrm{bitki}^{-1}\right)$ ilk yıl sera ortamından elde edilmiştir (Çizelge 5).

Çizelge 2. Farklı ortam ve faklı dikim zamanlarında elde edilen bitki boyuna (cm).

Table 2. Data about plant height $(\mathrm{cm})$ obtained at different medium and different time of planting.

\begin{tabular}{|c|c|c|c|c|c|c|c|c|c|c|c|c|}
\hline (YO) & (DZ) & 2017 & 2018 & Ort. & DZ & 2017 & 2018 & Ort. & YO & 2017 & 2018 & Ort. \\
\hline \multirow{3}{*}{ Sera } & Ocak & 121.75 & 102.25 & 112.00 & Ocak & 120.46 & 104.83 & 112.64 & Sera & 123.92 & 112.30 & 118.11 \\
\hline & Şubat & 123.33 & 102.25 & 112.79 & Şubat & 124.50 & 105.69 & 115.09 & Gölge Alan & 122.55 & 104.69 & 113.62 \\
\hline & Mart & 122.58 & 110.42 & 116.50 & Mart & 124.75 & 113.29 & 119.02 & & & & \\
\hline \multirow{3}{*}{ Gölge Alan } & Ocak & 119.17 & 107.42 & 113.29 & & & & & & & & \\
\hline & Şubat & 125.67 & 109.13 & 117.40 & & & & & & & & \\
\hline & Mart & 126.92 & 116.17 & 121.54 & & & & & & & & \\
\hline \multicolumn{2}{|c|}{ YOxDZ } & öd & öd & & $\mathrm{DZ}$ & öd & öd & & YO & öd & öd & \\
\hline
\end{tabular}

YO: Yetiştirme Ortamı. DZ: Dikim Zamanı.ö.d: önemli değil.

Çizelge 3. Farklı ortam ve faklı dikim zamanlarında elde edilen gövde sayılarına (adet bitki ${ }^{-1}$ ) ilişkin veriler.

Table 3. Data about stem numbers (pcs plant ${ }^{-1}$ ) obtained at different medium and different time of planting.

\begin{tabular}{ccrcccccccccc}
\hline YO & DZ & 2017 & 2018 & Ort. & DZ & 2017 & 2018 & Ort. & YO & 2017 & 2018 & Ort. \\
\hline \multirow{3}{*}{ Sera } & Ocak & 11.67 & 14.00 & 12.84 & Ocak & 12.08 & 14.04 & 13.06 & Sera & 10.05 & 13.56 & 11.805 \\
& Şubat & 9.41 & 14.75 & 12.08 & Şubat & 10.17 & 14.69 & 12.43 & Gölge Alan & 11.05 & 13.39 & 12.22 \\
& Mart & 9.03 & 12.83 & 10.93 & Mart & 9.46 & 12.50 & 10.98 & & & \\
\hline \multirow{2}{*}{ Gölge } & Ocak & 12.50 & 14.08 & 13.29 & & & & & & & \\
Alan & Şubat & 10.91 & 14.63 & 12.77 & & & & & & & \\
& Mart & 9.83 & 12.17 & 11.00 & & & & & & & \\
\hline \multicolumn{2}{l}{ YOxDZ } & öd & öd & & DZ & öd & öd & & YO & öd & öd \\
\hline
\end{tabular}

YO: Yetiştirme Ortamı. DZ: Dikim Zamanı. ö.d: önemli değil. 
Çizelge 4. Farklı ortam ve faklı dikim zamanlarında elde edilen taze yumru verimine ( $\mathrm{g}$ bitki $\left.{ }^{-1}\right)$ ilişkin veriler.

Table 4. Data about fresh tuber yield $\left(\mathrm{g} \mathrm{plant}^{-1}\right.$ ) obtained at different medium and different time of planting.

\begin{tabular}{|c|c|c|c|c|c|c|c|c|c|c|c|c|}
\hline YO & DZ & 2017 & 2018 & Ort. & DZ & 2017 & 2018 & Ort. & YO & 2017 & 2018 & Ort. \\
\hline \multirow{3}{*}{ Sera } & Ocak & 766.85 & $517.81 \mathrm{~B}$ & 766.9 & Ocak & 739.60 & $559.74 \mathrm{~B}$ & 649.67 & Sera & 946.72 & $811.51 \mathrm{~A}$ & 879.115 \\
\hline & Şubat & 1054.05 & $1076.75 \mathrm{~A}$ & 1054.05 & Şubat & 949.25 & $877.75 \mathrm{~A}$ & 913.50 & Gölge Alan & 800.61 & $648.54 \mathrm{~B}$ & 724.575 \\
\hline & Mart & 1019.27 & $1024.94 \mathrm{~A}$ & 1019.3 & Mart & 932.14 & $850.44 \mathrm{~A}$ & 891.29 & & & & \\
\hline \multirow{3}{*}{ Gölge Alan } & Ocak & 712.35 & $601.67 \mathrm{~B}$ & 712.35 & & & & & & & & \\
\hline & Şubat & 844.45 & $678.75 \mathrm{~B}$ & 844.45 & & & & & & & & \\
\hline & Mart & 845.02 & $675.95 \mathrm{~B}$ & 845.02 & & & & & & & & \\
\hline \multicolumn{2}{|c|}{ YOxDZ } & öd & $* *$ & & DZ & öd & $* *$ & & YO & öd & $* *$ & \\
\hline
\end{tabular}

YO: Yetiştirme Ortamı, DZ: Dikim Zamanı. ö.d: önemli değil, **: $\mathrm{P}<0.01$ düzeyinde önemlidir, *: $\mathrm{P}<0.05$ düzeyinde önemlidir.

Çizelge 5. Farklı ortam ve faklı dikim zamanlarında elde edilen kuru yumru verimine ( $\mathrm{g}$ bitki $\left.{ }^{-1}\right)$ ilişkin veriler.

Table 5. Data about dry tuber yield $\left(\mathrm{g} \mathrm{plant}^{-1}\right.$ ) obtained at different medium and different time of planting.

\begin{tabular}{|c|c|c|c|c|c|c|c|c|c|c|c|c|}
\hline YO & $\mathrm{DZ}$ & 2017 & 2018 & Ort. & $\mathrm{DZ}$ & 2017 & 2018 & Ort. & YO & 2017 & 2018 & Ort. \\
\hline \multirow{3}{*}{ Sera } & Ocak & 85.35 & $58.37 \mathrm{~B}$ & 71.86 & Ocak & $82.32 \mathrm{~B}$ & $62.98 \mathrm{~B}$ & 72.65 & Sera & $117.32 \mathrm{~A}$ & $93.79 \mathrm{~A}$ & 105.55 \\
\hline & Şubat & 137.43 & $115.51 \mathrm{~A}$ & 126.47 & Şubat & $118.16 \mathrm{~A}$ & $97.12 \mathrm{~A}$ & 107.64 & Gölge Alan & $92.13 \mathrm{~B}$ & $74.90 \mathrm{~B}$ & 83.51 \\
\hline & Mart & 129.17 & $132.00 \mathrm{~A}$ & 130.59 & Mart & $113.69 \mathrm{~A}$ & $105.07 \mathrm{~A}$ & 109.38 & & & & \\
\hline \multirow{3}{*}{$\begin{array}{l}\text { Gölge } \\
\text { Alan }\end{array}$} & Ocak & 79.28 & $67.59 \mathrm{~B}$ & 73.44 & & & & & & & & \\
\hline & Şubat & 98.89 & $78.73 \mathrm{~B}$ & 88.81 & & & & & & & & \\
\hline & Mart & 98.21 & $78.14 \mathrm{~B}$ & 88.18 & & & & & & & & \\
\hline \multicolumn{2}{|c|}{ YOxDZ } & öd & $* *$ & & $\mathrm{DZ}$ & $*$ & ** & & $\mathrm{YO}$ & $*$ & $* *$ & \\
\hline
\end{tabular}

YO: Yetiştirme Ortamı. DZ: Dikim Zamanı. ö.d: önemli değil. **: $\mathrm{P}<0.01$ düzeyinde önemlidir. *: $\mathrm{P}<0.05$ düzeyinde önemlidir.

Çalışmamızda ele alınan yumru verimi farklı araştırmacılar tarafından değerlendirilmiştir. Farklı organik materyallerin zencefilin çimlenme oran1, büyümesi ve verimi üzerine olan etkisinin araştırıldığ $\breve{g}_{1}$ çalş̧mada 12 litrelik saksılar kullanılmıştır. Her saksıda bir bitki olacak şekilde yürütülen çalışmada taze yumru verimi 29.27-128.66 $\mathrm{g} \mathrm{saks}^{-1}$ arasında değişim göstermiş̧ir (Sale ve ark. 2018). Woelore ve ark. (2016) ise, taze yumru ağırlığının 49.64-73.59 $\mathrm{g} \mathrm{bitki}^{-1}$ arasında değiştiğini bildirmişlerdir. Araştırmacıların elde ettiği taze yumru ağırlıkları, çalışmamız ile kıyaslandığında oldukça düşük olduğu görülmektedir. Bu sonuçlar, yetiştiricilik yapılan yerin toprak ve iklim özelliklerine ayrıca tarımsal girdilerin (yetiştirme ortamı, gübreleme, sulama vb.) türü ve uygulama miktarlarına göre farklılıklar olabileceğini göstermektedir. Islam ve ark. (2015), farklı sulama ve malç materyallerini konu aldıkları araştırmada, en yüksek taze yumru verimini $308.94 \mathrm{~g}$ bitki $^{-1}$ ile kurak dönemde sulama ve çeltik sap malcının kullanıldı ̆̆ uygulamadan elde etmişlerdir. Bu çalışmadan elde edilen bitki başına taze yumru verim değerleri (712.35-1054.05 $\left.\mathrm{g} \mathrm{bitki}^{-1}\right)$, Islam ve ark. (2015) tarafindan elde edilen sonuçlardan yaklaşık üç kat fazladır. Bu farklılık, yetiştiricilik yapılan yerin toprak ve iklim özelliklerinden kaynaklanabileceği gibi farklı çeşitlerin ve farklı kültürel uygulamaların sonucu olabileceği düşünülmektedir.

\subsection{Fenolik bileşenler (6-shogaol ve 6-gingerol)}

Üretimde, verim kadar önemli olan bir diğer faktör kalitedir. Kaliteyi etkileyen 6-shogaol miktarı Çizelge 6'de verilmiştir. 6-shogaol miktarı bakımından, ilk yıl dikim zamanı x yetiştirme ortamı interaksiyonu ve yetiştirme ortamları arası fark önemsiz bulunurken, dikim zamanı açısından değerler arasındaki fark \%1 düzeyinde önemli bulunmuştur. İkinci yıl ise, dikim zamanı $\mathrm{x}$ yetiştirme ortamı interaksiyonu önemsiz bulunurken, dikim zamanı $\% 5$, yetiştirme ortamı $\% 1$ düzeyinde önemli bulunmuştur. Çalışmada elde edilen 6-shogaol miktarı 1.14-4.06 $\mathrm{mg} \mathrm{g}^{-1}$ arasında değişim gösterirken, en yüksek değer (4.06 $\mathrm{mg} \mathrm{g}^{-1}$ ), ikinci y1l serada ocak ayı dikiminden elde edilmiştir. Kaliteyi etkileyen bir diğer bileşen ise gingerol miktarıdır. Her iki yılda da dikim zamanı x yetiştirme ortamı interaksiyonu ve dikim zamanı gingerol miktarı bakımından önemsiz bulunurken, yetiştirme ortamı ilk yıl \%1 ikinci yıl $\% 5$ düzeyinde önemli bulunmuştur. Gingerol miktarı, 3.00-7.19 $\mathrm{mg} \mathrm{g}^{-1}$ arasında değişim gösterirken, en yüksek değer sera şartlarında şubat dikiminden elde edilmiştir (Çizelge 7).

Hindistan'da 18 genotipte, hasatla birlikte ve hasattan 4 ay sonra 6-gingerol ve 6-Shogaol içerikleri tespit edilmiştir. 6-gingerol miktarı, 1.030-3.049 $\mathrm{mg} \mathrm{g}^{-1}$ arasında değişim gösterirken, 6-Shogaol içeriği, $0.026-0.36 \mathrm{mg} \mathrm{g}^{-1}$ arasında değişim göstermiştir (Sanwal ve ark. 2010). Suhaimi ve ark. (2018) tarafından yapılan çalışmada topraksız kültürde yetiştirilen zencefilin 6-gingerol içeriğinin yetiştirme periyodunda 3. aydan 9. aya kadar değişimi incelenmiştir. Taze yumruda 6-gingerol miktarı $0.754-2.546 \mathrm{mg} \mathrm{g}^{-1}$ arasında değişirken kuru yumruda $0.10-1.47 \mathrm{mg} \mathrm{g}^{-1}$ arasında değişim göstermiştir. Chumroenphat ve ark. (2018), soyulmuş ve soyulmamış zencefillerin 6-gingerol içeriğini incelemiş ve soyulmamış zencefillerde daha fazla 6-gingerol $(0.753 \pm 2.03$ $\mathrm{mg} \mathrm{g}^{-1}$ yaş ağırlık) olduğunu bildirmişlerdir. Kiran ve ark. (2013) tarafindan yürütülen çalışmada, 6. ve 9. ayda hasat edilen 10 farklı yerel zencefil çeşidinde, 6-gingerol oran1 $1.67-6.40 \mathrm{mg} \mathrm{g}^{-1}$ arasında değişim göstermiştir. En yüksek 6-gingerol oranı 6. ayda hasat edilen zencefillerde bulunmuştur. Yürütülen çalışmada, gingerol miktarı, (3.00-7.19 mg g-1) Kiran ve ark. (2013)'nin bulguları ile benzerlik gösterirken, Sanwal ve ark. (2010)'nin bulgularından yüksek bulunmuştur. Ayrıca çalışmada elde edilen 6-shogaol miktarı 1.14-4.06 $\mathrm{mg} \mathrm{g}^{-1}$ arasında değişim göstermiştir. Bu değerler, Sanwal ve ark. 2010'nin elde ettiği değerlerden oldukça yüksektir. Söz konusu araştırmalardan elde edilen bulgular arasındaki farklılıkların, numunenin analize hazırlanma şekli (Kiran ve ark. 2013), hasat zamanı (Sanwal ve ark. 2010), iklim ve çeşit/genotip kullanımından kaynaklandığı söylenebilir. 
Çizelge 6. Farklı ortam ve faklı dikim zamanlarında elde edilen 6-shogaol miktarına ( $\left.\mathrm{g} \mathrm{kg}^{-1}\right)$ ilişkin veriler.

Table 6. Data about 6-shogaol content $\left(\mathrm{g} \mathrm{kg}^{-1}\right)$ obtained at different medium and different time of planting.

\begin{tabular}{|c|c|c|c|c|c|c|c|c|c|c|c|c|}
\hline $\mathrm{YO}$ & DZ & 2017 & 2018 & Ort. & DZ & 2017 & 2018 & Ort. & $\mathrm{YO}$ & 2017 & 2018 & Ort. \\
\hline \multirow{4}{*}{ Sera } & Ocak & 1.54 & 4.06 & 2.80 & Ocak & $1.43 \mathrm{~A}$ & $3.23 \mathrm{~A}$ & 2.33 & Sera & 1.29 & $3.64 \mathrm{~A}$ & 2.465 \\
\hline & Şubat & 1.14 & 3.18 & 2.16 & Şubat & $1.15 \mathrm{~B}$ & $2.67 \mathrm{~B}$ & & Gölge & 1.22 & $2.34 \mathrm{~B}$ & \\
\hline & & & & & & & & 1.91 & Alan & & & 1.78 \\
\hline & Mart & 1.21 & 3.24 & 2.23 & Mart & $1.18 \mathrm{~B}$ & $2.77 \mathrm{~B}$ & 1.975 & & & & \\
\hline \multirow{3}{*}{$\begin{array}{l}\text { Gölge } \\
\text { Alan }\end{array}$} & Ocak & 1.33 & 2.40 & 1.87 & & & & & & & & \\
\hline & Şubat & 1.17 & 2.17 & 1.67 & & & & & & & & \\
\hline & Mart & 1.15 & 2.31 & 1.73 & & & & & & & & \\
\hline YOxDZ & & öd & öd & & DZ & $* *$ & $*$ & & YO & öd & *** & \\
\hline
\end{tabular}

Çizelge 7. Farklı ortam ve faklı dikim zamanlarında elde edilen gingerol miktarına $\left(\mathrm{mg} \mathrm{g}^{-1}\right)$ ilişkin veriler.

Table 7. Data about and gingerol content $\left(\mathrm{mg} \mathrm{g}^{-1}\right)$ obtained at different medium and different time of planting.

\begin{tabular}{|c|c|c|c|c|c|c|c|c|c|c|c|c|}
\hline $\mathrm{YO}$ & $\mathrm{DZ}$ & 2017 & 2018 & Ort. & $\mathrm{DZ}$ & 2017 & 2018 & Ort. & $\mathrm{YO}$ & 2017 & 2018 & Ort. \\
\hline \multirow{3}{*}{ Sera } & Ocak & 6.78 & 3.94 & 5.36 & Ocak & 6.06 & 3.97 & 5.02 & Sera & $6.87 \mathrm{~A}$ & $3.63 \mathrm{~B}$ & 5.25 \\
\hline & Şubat & 7.19 & 3.13 & 5.16 & Şubat & 6.42 & 3.81 & 5.12 & Gölge Alan & $5.27 \mathrm{~B}$ & $4.34 \mathrm{~A}$ & 4.81 \\
\hline & Mart & 6.63 & 3.42 & 5.03 & Mart & 5.72 & 4.06 & 4.89 & & & & \\
\hline \multirow{3}{*}{$\begin{array}{l}\text { Gölge } \\
\text { Alan }\end{array}$} & Ocak & 5.35 & 3.00 & 4.17 & & & & & & & & \\
\hline & Şubat & 5.65 & 4.5 & 5.08 & & & & & & & & \\
\hline & Mart & 4.81 & 4.71 & 4.76 & & & & & & & & \\
\hline YOxDZ & & öd & öd & & $\mathrm{DZ}$ & öd & öd & & YO & $* *$ & $*$ & \\
\hline
\end{tabular}

YO: Yetiştirme Ortamı. DZ: Dikim Zamanı. ö.d: önemli değil. **: $\mathrm{P}<0.01$ düzeyinde önemlidir. *: $\mathrm{P}<0.05$ düzeyinde önemlidir.

\subsection{Uçucu yağ ve bileşenleri}

Çalışmadan elde edilen uçucu yă̆ oranları Çizelge 8'de verilmiştir. Çizelgede de görüldüğü gibi, her iki yılda da uçucu yağ oranları bakımından, dikim zamanı x yetiştirme ortamı interaksiyonu ve dikim zamanı önemsiz bulunmuştur. Yetiştirme ortamı ise ikinci yıl \%1 düzeyinde önemli çıkmıştır. Yetiştirme ortamı bakımında en yüksek uçucu yağ oranı $\% 1.36$ ile ikinci yıl sera ortamından elde edilmiştir. Elde edilen uçucu yağda, zingiberene, beta-sesquiphellandrene, beta-bisabolene ana bileşenler olarak tespit edilmiştir. Zingiberene oranı açısından her iki yılda da dikim zamanı x yetiştirme ortamı interaksiyonu önemsiz bulunmuştur. Dikim zamanı bakımından ilk y1l ve yetiştirme ortamı bakımından ikinci yıl \%1 düzeyinde zingiberene oranı önemli çıkmıştır. Çizelge 9'da görüldüğü gibi zingiberene ilk y1l \%36.37-\%44.85 arasında değişim gösterirken, ikinci yı1 \%36.91-\%42.00 arasında tespit edilmiştir. En yüksek zingiberene oranı ise, $(\% 44.85)$ ilk y1l gölgelik alanda şubat dikiminden elde edilmiştir. $\beta$-sesquiphellandrene oranı açısından dikim zamanı ilk yıl $\% 1$, yetiştirme ortamı ikinci y1l \%5 düzeyinde önemli bulunmuştur (Çizelge 10). $\beta$-bisabolene oranı bakımından ise, ilk yıl dikim zamanı $\% 1$ düzeyinde önemliyken, diğer konular her iki yılda da önemsiz çıkmıştır (Çizelge 11). En yüksek $\beta$-sesquiphellandrene oranı (\%24.45) ikinci y1l sera ortamında mart dikiminde tespit edilirken, en yüksek $\beta$-bisabolene (\%13.53) oranı, ilk yıl sera ortamında mart dikiminde tespit edilmiştir.

Vietnam'dan temin edilen zencefillerin su ve buhar damıtması ile uçucu yağ oranlarının belirlendiği bir çalışmada uçucu yağ oranları sırasıyla $\% 2.05$ ve $\% 2.10$ olarak tespit edilmiştir. Su damıtması ile elde edilen uçucu yağın ana bileşenleri ar-curcumene (\%11.7) ve $\beta$-bisabolene (\%4.1) olarak bildirilirken, buhar damıtmayla elde edilen uçucu yağın ana bileşenleri ise, ar-curcumene, (\%12.6), $\alpha$-zingiberene (\%10.3), $\beta$-bisabolen (\%8.1) ve p-sesquiphellandrene (\%7.4) olarak bildirilmiştir (Stoyanova ve ark. 2015). Bu çalışmalarda elde edilen uçucu yağ oranı, elde ettiğimiz uçucu yağ oranlarından daha yüksek bulunurken, uçucu yağ bileşenleri açısından farklılık göstermektedir. Ana bileşen olarak tespit ettiğimiz zingiberene (\%44.85) $\beta$-Sesquiphellandrene $(\% 24.45)$ ve $\beta$ bisabolen (\%13.53) oranları açısından kıyaslayacak olursak, bu çalışmalardan elde edilen uçucu yağ bileşenlerinin daha düşük olduğu görülmektedir. Kizhakkayil ve Sasikumar (2014), yaptıkları çalışmada, zencefil uçucu yağında 60 bileşen tanımlamışlardır. Zingiberene oranını \%17.60-29.60, $\beta$ sesquiphellandrene oranın $\%$ 7.06-12.10 ve beta bisabolene oranını ise \%2.41-7.34 arasında olduğunu tespit ederlerken, Jeena ve ark. (2013), ana bileşen olarak zingiberen (\%31.08), ar-curcumene (\%15.4), a-sesquiphellandrene (\%14.02), bisabolen, (\%13.80) ve sabinene (\%8.27)'i tespit etmişlerdir. Kiran ve ark. (2013), Kuzey-Doğu Hindistan'dan temin edilen 17 çeşit taze zencefilde yürüttükleri çalışmada; ortalama zingiberene, beta sesquiphellandrene ve beta bisabolene oranlarını sirasıyla; \%20.98, \%7.96 ve \%4.99 olarak bulmuşlardır. Çalışmamızdan elde edilen zingiberene (\%44.85) $\beta$-Sesquiphellandrene $(\% 24.45)$ ve $\beta$-bisabolen $(\% 13.53)$, bu çalışmalardan elde edilen uçucu yağ ana bileşenleri ile benzerlik göstermekle birlikte, bileşen oranları açısından daha yüksektir. Kiran ve ark. (2013) tarafindan yürütülen çalışmada, uçucu yăg bileşenleri açısından zencefil çeşitleri arasında geniş bir varyasyon olduğu bildirilmiştir. Uçucu yağda 30 bileşen tanımlanırken, geranial, zingiberene, ar-curcumene, camphene, neral, $\beta$-sesquiphellandrene ve $\beta$-bisabolene bileşenleri ana bileşenler olarak belirlenmiştir. Zingiberene, $\beta$ sesquiphellandrene ve $\beta$-bisabolene bileşenleri sırasıyla; \%5.84-24.00, \%3.69-8.57, \%2.12-5.86 arasında bulunmuştur. El-Baroty ve ark. (2010) zencefil uçucu yağında yaptıkları çalışmada; $\beta$-sesquiphellandrene (\%27.16), caryophyllene (\%15.29), zingiberene (\%13.97), $\alpha$-farnesene (\%10.52) ve arcurcumene (\%6.62)'i ana bileşenler olarak tespit ederlerken, Höferl ve ark. (2015), ana bileşenler olarak ise, $\alpha$-zingiberene (\%17.4), geranial (\%10.5), neral (\%9.1), camphene (\%7.8), $\alpha$-farnesene (\%6.8) ve $\beta$-sesquiphellandrene (\%6.7)'i tespit etmişlerdir. Hindistan'da yetiştirilen iki çeşitte, 60 uçucu yağ bileşeni tespit edilmiştir. Bhaisa çeşidinde ana bileşenler olarak geranyl acetate $(\% 18.8)$, zingiberene $(\% 6.3)$ ve geranial (\%8.2) tespit edilirken, Majulay çeşidinde zingiberene (\%19.8) ve geranial (\%16.5) tespit edilmiştir (Sasidharan ve ark. 2012). Bu 
Çizelge 8. Farklı ortam ve faklı dikim zamanlarında elde edilen uçucu yağ oranlarına (\%) ilişkin veriler.

Table 8. Data about essential oil rates (\%) obtained at different medium and different time of planting.

\begin{tabular}{|c|c|c|c|c|c|c|c|c|c|c|c|c|}
\hline $\mathrm{YO}$ & $\mathrm{DZ}$ & 2017 & 2018 & Ort. & $\mathrm{DZ}$ & 2017 & 2018 & Ort. & $\mathrm{YO}$ & 2017 & 2018 & Ort. \\
\hline \multirow{3}{*}{ Sera } & Ocak & 0.92 & 1.34 & 1.13 & Ocak & 0.98 & 1.18 & & Sera & 1.10 & $1.36 \mathrm{~A}$ & 1.23 \\
\hline & Şubat & 1.30 & 1.50 & 1.4 & Şubat & 1.08 & 1.21 & & Gölge Alan & 0.95 & $0.95 \mathrm{~B}$ & 0.95 \\
\hline & Mart & 1.08 & 1.25 & 1.17 & Mart & 1.00 & 1.08 & & & & & \\
\hline \multirow{3}{*}{$\begin{array}{l}\text { Gölge } \\
\text { Alan }\end{array}$} & Ocak & 1.05 & 1.03 & 1.04 & & & & & & & & \\
\hline & Şubat & 0.87 & 0.91 & 0.89 & & & & & & & & \\
\hline & Mart & 0.93 & 0.91 & 0.92 & & & & & & & & \\
\hline YOxDZ & & öd & öd & & $\mathrm{DZ}$ & öd & öd & & $\mathrm{YO}$ & öd & $* *$ & \\
\hline
\end{tabular}

YO: Yetiştirme Ortamı. DZ: Dikim Zamanı. ö.d: önemli değil. **: $\mathrm{P}<0.01$ düzeyinde önemlidir. *: $\mathrm{P}<0.05$ düzeyinde önemlidir.

Çizelge 9. Farklı ortam ve faklı dikim zamanlarında elde edilen uçucu yağdaki Zingiberene oranları (\%).

Table 9. Zingiberene rates (\%) obtained at different medium and different time of planting.

\begin{tabular}{|c|c|c|c|c|c|c|c|c|c|c|c|c|}
\hline $\mathrm{YO}$ & $\mathrm{DZ}$ & 2017 & 2018 & Ort. & $\mathrm{DZ}$ & 2017 & 2018 & Ort. & $\mathrm{YO}$ & 2017 & 2018 & Ort. \\
\hline \multirow{3}{*}{ Sera } & Ocak & 37.50 & 37.30 & 37.40 & Ocak & $37.00 \mathrm{~B}$ & 39.60 & 38.30 & Sera & 40.20 & $36.00 \mathrm{~B}$ & 38.10 \\
\hline & Şubat & 43.00 & 33.80 & 38.40 & Şubat & $43.90 \mathrm{~A}$ & 37.20 & 40.55 & Gölge Alan & 39.90 & $40.10 \mathrm{~A}$ & 40.00 \\
\hline & Mart & 40.00 & 36.90 & 38.45 & Mart & $39.20 \mathrm{~B}$ & 37.40 & 38.30 & & & & \\
\hline \multirow{3}{*}{$\begin{array}{l}\text { Gölge } \\
\text { Alan }\end{array}$} & Ocak & 36.40 & 42.00 & 39.20 & & & & & & & & \\
\hline & Şubat & 44.90 & 40.60 & 42.75 & & & & & & & & \\
\hline & Mart & 38.40 & 37.80 & 38.10 & & & & & & & & \\
\hline YOxDZ & & öd & öd & & $\mathrm{DZ}$ & $* *$ & öd & & YO & öd & $* *$ & \\
\hline
\end{tabular}

Çizelge 10. Farklı ortam ve faklı dikim zamanlarında elde edilen uçucu yağdaki beta sesquiphellandrene oranları (\%).

Table 10. Beta sesquiphellandrene rates (\%) obtained at different medium and different time of planting.

\begin{tabular}{|c|c|c|c|c|c|c|c|c|c|c|c|c|}
\hline $\mathrm{YO}$ & $\mathrm{DZ}$ & 2017 & 2018 & Ort. & $\mathrm{DZ}$ & 2017 & 2018 & Ort. & $\mathrm{YO}$ & 2017 & 2018 & Ort. \\
\hline \multirow{3}{*}{ Sera } & Ocak & 19.60 & 23.50 & 21.55 & Ocak & $18.50 \mathrm{~B}$ & 23.20 & 20.85 & Sera & 21.2 & $23.7 \mathrm{~A}$ & 22.45 \\
\hline & Şubat & 21.80 & 23.10 & 22.45 & Şubat & $22.00 \mathrm{~A}$ & 22.40 & 22.20 & Gölge Alan & 20.5 & $22.0 \mathrm{~B}$ & 21.25 \\
\hline & Mart & 22.30 & 24.40 & 23.35 & Mart & $22.10 \mathrm{~A}$ & 22.90 & 22.50 & & & & \\
\hline \multirow{3}{*}{$\begin{array}{l}\text { Gölge } \\
\text { Alan }\end{array}$} & Ocak & 17.30 & 22.80 & 20.05 & & & & & & & & \\
\hline & Şubat & 22.30 & 21.70 & 22.00 & & & & & & & & \\
\hline & Mart & 21.80 & 21.40 & 21.60 & & & & & & & & \\
\hline YOxDZ & & öd & öd & & $\overline{D Z}$ & $* *$ & öd & & $\mathrm{YO}$ & öd & $*$ & \\
\hline
\end{tabular}

Çizelge 11. Farklı ortam ve faklı dikim zamanlarında elde edilen uçucu yağdaki beta bisabolene oranları (\%).

Table 11. Beta bisabolene rates (\%) obtained at different medium and different time of planting.

\begin{tabular}{|c|c|c|c|c|c|c|c|c|c|c|c|c|}
\hline $\mathrm{YO}$ & $\mathrm{DZ}$ & 2017 & 2018 & Ort. & $\mathrm{DZ}$ & 2017 & 2018 & Ort. & $\mathrm{YO}$ & 2017 & 2018 & Ort \\
\hline \multirow{3}{*}{ Sera } & Ocak & 7.07 & 7.79 & 7.43 & Ocak & $6.65 \mathrm{C}$ & 8.02 & 7.34 & Sera & 9.62 & 7.80 & 8.71 \\
\hline & Şubat & 8.27 & 7.54 & 7.91 & Şubat & $8.08 \mathrm{~B}$ & 7.60 & 7.84 & Gölge Alan & 9.20 & 7.74 & 8.47 \\
\hline & Mart & 13.53 & 8.08 & 10.81 & Mart & $13.51 \mathrm{~A}$ & 7.70 & 10.61 & & & & \\
\hline \multirow{3}{*}{$\begin{array}{l}\text { Gölge } \\
\text { Alan }\end{array}$} & Ocak & 6.23 & 8.25 & 7.24 & & & & & & & & \\
\hline & Şubat & 7.89 & 7.66 & 7.78 & & & & & & & & \\
\hline & Mart & 13.49 & 7.31 & 10.40 & & & & & & & & \\
\hline YOxD2 & & öd & öd & & $\mathrm{DZ}$ & $* *$ & öd & & $\mathrm{YO}$ & öd & öd & \\
\hline
\end{tabular}

YO: Yetiştirme Ortamı. DZ: Dikim Zamanı. ö.d: önemli değil. **: $\mathrm{P}<0.01$ düzeyinde önemlidir. *: $\mathrm{P}<0.05$ düzeyinde önemlidir.

çalıșmalardan elde edilen ana bileşen ve oranları, Antalya şartlarında sera ve gölge alanda yetiştirilen zencefil yumrularından elde edilen uçucu yağ bileşenlerinden oldukça farklıdır ve oranlar düşüktür. Bunun nedeninin farklı iklim ve toprak özelliklerinden kaynaklanabileceği gibi, kullanılan çeşit ve çevre şartlarının farklılığından da kaynaklanabileceği tahmin edilmektedir. Nitekim, Avustralya'da yapılan bir çalışmada, zencefil yağının önemli miktarda bileşimsel çeşitlilik gösterdiği ancak tipik olarak genellikle, zingiberene, ar-curcumene, $\beta$-bisabolene, ve $\beta$-sesquiphellandrene içerdiği bildirilmiştir.
Ayrıca Avustralya zencefil yağının, neral ve geranial (\%51-71) izomerlerin yüksek içeriği nedeniyle belirli bir "lemonya" aromasına sahip olduğunu ve bu bileşenlerin, genellikle toplu olarak sitral olarak adlandırıldığını bildirmişlerdir (Wohlmuth ve ark. 2006). Ekundayo (1988), Nijerya orjinli taze ve kuru zencefil yumrularında yürüttüğü çalışmada, taze yumrularda uçucu yağ oranını \%1.02 ve kuru yumrularda uçucu yağ oranını $\% 1.84$ belirlemiştir. Taze yumru uçucu yağ ana bileşenleri, Geranial (\%15.02), $\quad \beta$-Zingiberene (\%12.24), 1.8-cineole (\%10.47)'den oluşurken, kuru yumru uçucu yağ ana bileşenleri, 
$\beta$-Zingiberene (\%28.14), $\beta$-Sesquiphellandrene (\%10.61) ve Geranial (\%9.01)'den oluşmuştur. Stoyanova ve ark. (2015), su damıtması ile elde edilen uçucu yağın ana bileşenlerini ar-curcumene $(\% 11.7)$ ve $\beta$-bisabolen $(\% 4.1)$ olarak bildirirlerken, buhar damıtmayla elde edilen uçucu yağın ana bileşenlerini ar-curcumene, (\%12.6), $\alpha$-zingiberen (\%10.3), $\beta$ bisabolen (\%8.1) ve p-sesquiphellandrene (\%7.4) olarak bildirmişlerdir. Uçucu yağdaki ana bileşen ve bileşenlerin oranlarının farklılık gösterdiği yapılan çalışmalarda görülmektedir. Ana bileşen ve bileşenlerin oransal değişimi, farklı iklim ve toprak özellikleri, farklı çeşit ve çevre şartlarından kaynaklanabileceği gibi uçucu yağı çıkarma zamanı, yöntemi ve farklı ekstraksiyon yöntemlerinin kullanılmasından da kaynaklanabilir.

\section{Sonuç}

Sonuç olarak; tropik ve yarı tropik iklimlerde yetiştiriciliği yapılan zencefile ait ülkemizde adaptasyon çalı̧̧malarına başlamış olup, yetiştirilme potansiyeli olduğu düşünülmektedir. Antalya iklim şartlarında sera koşullarında, şubat dikimi en uygun dikim zamanı olarak belirlenmiştir. Ancak, farklı bölgelerde, farklı toprak yapısı olan yerlerde ve rakımlarda; farklı konuların çalışılması (fide optimizasyonu, çeşit, gübreleme, malçlama vb.) Türkiye'de zencefil tarımının gelişmesine fayda sağlayacaktır. Zencefilin olası potansiyelleri göz önüne alındığında, bu bitkinin ülke tarımına kazandırılması gerektiği düşünülmektedir.

\section{Kaynaklar}

Arslan N, Baydar H, Kızıl S, Karık Ü, Şekeroğlu N, Gümüşçü A (2015) Tıbbi aromatik bitkiler üretiminde değişimler ve yeni arayışlar. Türkiye Ziraat Mühendisliği VIII. Teknik Kongresi, Ankara, pp. 483-507.

Babu MS, Kumar BP, Swami DV, Krishna KU, Emmanuel N (2017) Performance of ginger (Zingiber officinale Rosc.) varieties under shade net condition of costal Andhra Pradesh. International Journal of Current Microbiology and Applied Sciences 6 (7): 494-498.

Cemeroğlu B (2010) Gıda Analizleri. 2. Baskı, Gıda Teknolojisi Derneği Yayınları, Ankara.

Chumroenphat R, Somboonwatthanakul I, Butkhup L, Saensouk S (2018) 6-gingerol content of ginger (Zingiber officinale Roscoe) by different drying methods. In: Botanical Reserach in Tropical Asia. Vientiane.

Egbuchua CN, Enujeke EC (2013) Growth and yield responses of ginger (Zingiber officinale) to three sources of organic manures in a typical rainforest zone, Nigeria. Journal of Horticulture and Forestry 5(7): 109-114.

Ekundayo O, Laakso I, Hiltunen R (1988) Composition of ginger (Zingiber officinale Roscoe) volatile oils from Nigeria. Flavour and Fragrance Journal 3(2): 85-90.

El-Baroty GS, Abd El-Baky HH, Farag RS, Saleh MA (2010) Characterization of antioxidant and antimicrobial compounds of cinnamon and ginger essential oils. Indian African Journal of Biochemistry Research 4(6): 167-174.

Fischer UA, Carle R, Kammerer DR (2011) Identification and quantification of phenolic compounds from pomegranate (Punica granatum L.) peel, mesocarp, aril and differently produced juices by HPLC-DAD-ESI/MSn. Food Chemistry 127(2): 807-821.

Ghosh S, Mandi SS (2011) Study of genetic variation among some wild landraces of Zingiber officinale Roscoe correlated with their antioxidant potential status. Journal of Molecular Biology Research 1(1): 77-87.
Gülümser A, Bozoğlu H, Pekşen E (2006) Araştırma ve deneme metotları. Ondokuz Mayıs Üniversitesi, Ziraat Fakültesi, Ders Kitab1: 48, s. 264.

Hayden AL, Brigham LA, Giacomelli LA (2004) Aeroponic cultivation of ginger (Zingiber officinale) rhizomes. VII International Symposium on Protected Cultivation in Mild Winter Climates Volume 659, Florida, pp. 397-402.

Hepperly P, Zee, F, Kai, R, Arakawa C, Meisner M, Kratky B, Hamamoto K, Sato D (2004) Producing bacterial wilt-free ginger in greenhouse culture. Soil and Crop Management 8: 1-6.

Hoagland DR, Arnon DI (1950) The water-culture method for growing plants without soil. California Agriculture Experiment Station Circular 347(2): 32.

Höferl M, Stoilova I, Wanner J, Schmidt E, Jirovetz L, Trifonova D, Stanchev V, Krastanov A (2015) Composition and comprehensive antioxidant activity of ginger (Zingiber officinale) essential oil from Ecuador. Natural Product Communications 10(6): 1085-1090.

Islam MA, Rahim MA, Iqbal TMT (2015) Effect of irrigation and mulching on growth and yield of ginger. Bangladesh Agronomy Journal 18(1): 27-36.

Jeena K, Liju VB, Kuttan R (2013) Antioxidant, anti-inflammatory and antinociceptive activities of essential oil from ginger. Indian Journal of Physiology and Pharmacology 57(1): 51-62.

Kemper KJ (1999) Ginger (Zingiber officinale). The logwood herbal task force. http://t.longwoodherbal.org/ginger/ginger.pdf. Erişim 29 Mayıs 2019.

Kiran CR, Chakka AK, Padmakumari Amma KP, Nirmala Menon A, Sree Kumar MM, Venugopalan VV (2013) Influence of cultivar and maturity at harvest on the essential oil composition, oleoresin and [6]-Gingerol contents in fresh ginger from Northeast India. Journal of Agricultural and Food Chemistry 61: 4145-4154.

Kizhakkayil J, Sasikumar B (2014) Characterization of ginger (Zingiber officinale Rosc.) germplasm based on volatile and non-volatile components. African Journal of Biotechnology 11(4): 777-786.

Nair KP (2013) The Agronomy and Economy of Turmeric and Ginger. 1st Edition, Elsevier, Waltham.

Pandey SBS, Pandey M, Jadeja DB, Tandel MB, Nayak D (2017) Growth and yield of ginger (Zingiber officinale L) under SapotaJatropha based agroforestry systems in south Gujarat. Journal of Pharmacognosy and Phytochemistry 6(6): 247-251.

Sale FA, Adah H, Edibo E (2018) Effect of potting mixtures on germination, growth and yield of ginger (Zingiber officinale) in Anyigba. International Journal of Forestry and Horticulture 4(2): 713.

Sanwal SK, Yadav RK, Singh PK, Buragohain J, Verma MR (2010) Gingerol content of different genotypes of ginger (Zingiber officinale). Indian Journal of Agricultural Sciences 80(3): 258-60.

Sasidharan I, Venugopal VV, Nirmala Menon A (2012) Essential oil composition of two unique ginger (Zingiber officinale Roscoe) cultivars from Sikkim. Natural Product Research 19: 1759-1764.

Stoyanova A, Konakchiev A, Damyanova S, Stoilova I, Suu Thi P (2015) Composition and antimicrobial activity of ginger essential oil from Vietnam. doi: 10.1080/0972060X.2006.10643478.

Suhaimi MY, Adzemi MA, Wan Zaliha WS (2018) Effect of organic substrates on ginger growth,yield and [6]-gingerol content cultivated using soilless culture system. AGROFOR International Journal 3(1): 122-131.

Temel M, Tinmaz AB, Öztürk M, Gündüz O (2018) Dünyada ve Türkiye'de tıbbi -aromatik bitkilerin üretimi ve ticareti. Kahramanmaraş Sütçü İmam Üniversitesi Tarım ve Doğa Dergisi 21(Özel Sayı): 198-214.

Tropical Biodiversity (2020) Ginger ( Zingiber officinale Rosc.): Aromatic spice and medicinal herb. http://blogs.reading.ac.uk/tropical-biodiversity/2014/02/ginger- 
zingiber-officinale-rosc-aromatic-spice-and-medicinal-herb/. Accessed 27 April 2010.

TSE (2011) Baharatlar, çeşniler ve tıbbi bitkiler - Uçucu yăg muhtevasının tayini (hidrodistilasyon yöntemi). Türk Standartları Enstitüsü, TS EN ISO 6571, Ankara.

Uysal Bayar F, Çınar O (2020) Kültür koşullarında yetiştirilen farklı Origanum spp. türlerinin bazı verim ve kalite parametreleri. Derim 37(1): 10-17.

White F, Motomura S, Miyasaka S, Kratkyi BA (2013) A simplified method of multiplying bacterial wilt-free edible ginger (Zingiber officinale) in pots. Plant Disease 93: 1-3.
Woelore WM, Tesfaye B, Gedebo A (2016) Effects of sett size and spacing on the growth and yield of ginger (Zingiber officinale Rosc.) at Areka, Wolaita, Southern Ethiopia. Journal of Natural Sciences Research 6(19): 1-23.

Wohlmuth H, Smith MK, Brooks LO, Myers SP, Leach DN (2006) Essential oil composition of diploid and tetraploid clones of ginger (Zingiber officinale Roscoe) grown in Australia. Journal of Agricultural and Food Chemistry 54: 1414-1419. 